\title{
Correction to: One anastomosis gastric bypass vs. Roux-en-Y gastric bypass, remedy for insufficient weight loss and weight regain after failed restrictive bariatric surgery
}

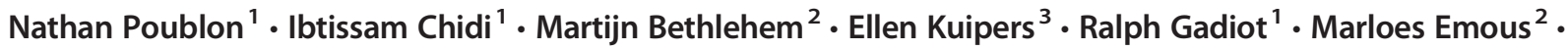 \\ Marc van Det ${ }^{3} \cdot$ Martin Dunkelgrun $^{1} \cdot$ Ulas Biter $^{1} \cdot$ Jan Apers ${ }^{1}$
}

Published online: 8 May 2020

(C) The Author(s) 2020

\section{Correction to: Obesity Surgery.}

https://doi.org/10.1007/s11695-020-04536-x

In the original article there was a discrepancy between the XML (online) version of the article and the PDF. The XML version is correct but the Results section and the tables were inadvertently omitted from the PDF. The PDF has been updated to restore the omitted material.

The online version of the original article can be found at https://doi.org/ 10.1007/s11695-020-04536-x

Nathan Poublon

napoublon@gmail.com

1 Department of Surgery, Franciscus Gasthuis \& Vlietland, Locatie

Gasthuis Afdeling Heelkunde, Kleiweg 500, 3045, PM

Rotterdam, The Netherlands

2 Department of Surgery, Medisch Centrum Leeuwarden, Leeuwarden, The Netherlands

3 Department of Surgery, Ziekenhuisgroep Twente, Almelo, The Netherlands 